\section{First record of Eubroncus from India (Hymenoptera: Chalcidoidea: Mymaridae), with description of a new species}

\author{
Mohammad Hayat ${ }^{1} \&$ F.R. Khan ${ }^{2}$ \\ 1,2 Department of Zoology, Aligarh Muslim University, Aligarh, Uttar \\ Pradesh 202002, India \\ Email: ${ }^{1}$ mohd_hayat@ rediffmail.com; ${ }^{2}$ insectgh11@gmail.com
}

The genera Eubroncus and Stomarotrum were described by Yoshimoto, Kozlov and Trjapitzin (1972). The type species of Eubroncus, E. orientalis, was based on two males collected in Selangor (Malaysia) and the type species of Stomarotrum, $S$. prodigiosum, was based on a female collected in the Primorskii krai (Russia). Triapitsyn \& Huber (2000) subsequently synomynized Stomarotrum with Eubroncus (Triapitsyn \& Berezovskiy 2002). More recently Triapitsyn and Berezovskiy (2002) redescribed E. prodigiosus (Yoshimoto et al. 1972) based on females and males collected in Primorskii krai, and indicated that E. orientalis Yoshimoto et al. is represented by males from localities in the Oriental and Australasian regions.

One of us (FRK) collected a single female of Eubroncus from Gorabari (Darjeeling District, West Bengal, India) which proved to belong to an undescribed species. It is described as $E$. indicus, sp. nov.

\section{Eubroncus indicus sp. nov. (Images 1-6)}

\section{Material examined}

Holotype: Female, 15.vi.2008, (on card, with right wings and antenna on slide), Gorabari, Darjeeling, West Bengal, India, coll. F.R. Khan. Holotype deposited in Insect collection, Department of Zoology, Aligarh Muslim University, Aligarh (ZDAMU), Reg.No. HYM/CH. 568.

Date of publication (online): 26 August 2009

Date of publication (print): 26 August 2009

ISSN 0974-7907 (online) | 0974-7893 (print)

Editor: T.C. Narendran

\section{Manuscript details:}

Ms \# 02079

Received 11 October 2008

Final received 07 July 2009

Finally accepted 08 August 2009

Citation: Hayat, M. \& F.R. Khan (2009). First record of Eubroncus from India (Hymenoptera: Chalcidoidea: Mymaridae), with description of a new species. Journal of Threatened Taxa 1(8): 439-440.

Copyright: ( Mohammad Hayat \& F.R. Khan 2009. Creative Commons Attribution 3.0 Unported License. JoTT allows unrestricted use of this article in any medium for non-profit purposes, reproduction and distribution by providing adequate credit to the authors and the source of publication.

Acknowledgements: We are thankful to the Indian Council of Agricultural Research, New Delhi and Dr. V.V. Ramamurthy, Division of Entomology, Indian Agricultural Research Institute, New Delhi, India, the National Coordinator of the "Network Project on Insect Biosystematics" for financial assistance. We are also grateful to the authorities of the Aligarh Muslim University and to the Chairman, Department of Zoology, for providing facilities

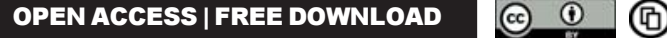

\section{Etymology}

The species name is based on the country of origin of the specimen.

\section{Description}

Female: (Holotype) Body length, 1.14mm. Body completely dark brown (Image 1); head, thorax and petiole nearly black, highly metallic and shiny. Antenna dark brown except radicle yellow. Mandibles brownish-yellow. Wings infuscate, the infuscation prominent below venation. Legs dark brown, especially coxae; fourth tarsal segment of mid and hind legs, and tarsal segments 3 and 4 of fore legs brown; remaining tarsal segments pale brownish yellow.

This species is similar to E. prodigiosus in sculpture and setation but differs in dimensions of various body parts as follows:

Head in dorsal view $1.2 \mathrm{x}$ as long as wide and, in profile, $1.33 \mathrm{x}$ as long as high; eyes oval, broadest anteroventrally and narrower posterodorsally, $1.4 \mathrm{x}$ as long as broad (7: 5) (Image $2)$; ocelli small, ocellar triangle with apical angle strongly obtuse; posterior ocelli about two ocellar diameters from occipital ridge. Mandibles slightly longer than length of vertex (14: 13.5) and shorter than dorsal length of head (14: 18) (Image 2). Antenna as in Image 3; scape about 5.5x as long as broad.

Thorax only slightly longer than length of petiole and gaster combined (32.5: 29.5) and slightly more than $2 \mathrm{x}$ as long as broad (32.5: 15); pronotum $1.55 \mathrm{x}$ as broad as long (14:9) and slightly longer than mesoscutum (9:8); median length of propodeum $0.8 \mathrm{x}$ of mesoscutum length $(6.5: 8)$ and $0.76 \mathrm{x}$ length of scutellum (anterior and posterior scutellum combined) (6.5: $8.5)$; apex of propodeum with a small tooth at posterolateral margin on each side; propodeum in mesal third with a nearly ' $U$ '- shaped ridge. Wings as in Images 4-6, basal setation as in E. prodigiosus, but hypochaeta almost as long as width of wing at that point.

Petiole $1.62 \mathrm{x}$ as long as broad, with short spine like projection from each side anterolaterally.

Gaster shorter than thorax (23: 32.5); TI (first tergite) smooth, without any ridges or carinae; $\mathrm{T}$ I occupying $0.45 \mathrm{x}$ gaster length: T II occupying 0.32x of gaster length, remaining tergites very narrow and partly retracted; ovipositor short, not exserted at apex.

Male: Unknown.

Host: Unknown.

Comments: Eubroncus indicus sp. nov. resembles E. prodigiosus in general body colour, sculpture and setation, including the undivided pronotum, but differs in dimensions of various body parts. Eubroncus indicus has oval shaped eyes, the scape about $5.5 \mathrm{x}$ as long as broad, the petiole $1.62 \mathrm{x}$ as long as broad, and TI of gaster nearly smooth. (In E. prodigiosus, based on the description given by Triapitsyn \& Berezovskiy 2002: the eyes are circular; the scape about $3 \mathrm{x}$ as long as broad; the petiole about as long as broad, and $\mathrm{T} I$ of gaster with prominent ridges and carinae.)

\section{References}

Triapitsyn, S.V. \& V.V. Berezovskiy (2002). Review of the Mymaridae (Hymenoptera, Chalcidoidea) of Primorskii krai: Genera Anagroidea Girault and Eubroncus Yoshimoto, Kozlov et Trjapitzin. Far Eastern Entomologist, No.114: 1-17

Yoshimoto, C.M., M.A. Kozlov \& V.A. Trjapitzin (1972). A new subfamily of Mymaridae (Hymenoptera, Chalcidoidea). [In Russian]. 

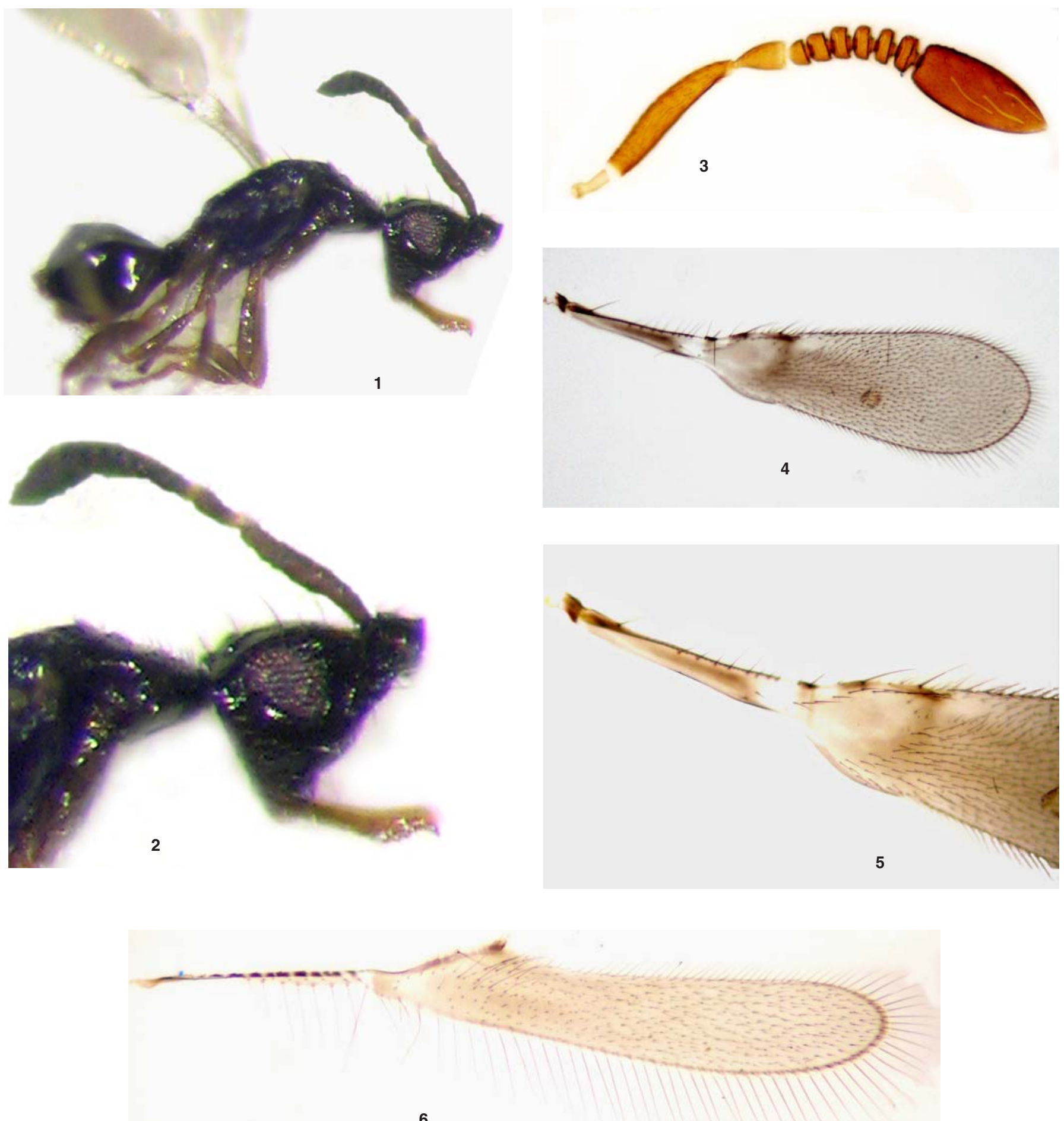

6

Images 1-6. Eubroncus indicus sp. nov., female

1 - body lateral; 2 - head and pronotum, lateral; 3 - antenna; 4 - fore wing; 5 - basal part of fore wing; 6 - hind wing.

Entomologicheskoe Obozrenie, 51: 878-885. 